\title{
MANIFESTATION OF BRONCHIAL REACTIVITY IN THE WORKERS EXPOSED TO VARIOUS GASES AT THE GASIFICATION DEPARTMENT OF THE POWER PLANTS OF KOSOVO
}

\author{
PELLUMB ISLAMI $^{1}$, ADNAN BOZALIJA ${ }^{2 *}$, HILMI ISLAMI ${ }^{3}$ \\ ${ }^{1}$ Department of Clinical Toxicology, Hospital of Mitrovica, Kosova. ${ }^{2}$ Department of Pharmacy, Faculty of Medicine, \\ University of Prishtina, Clinical Centre, Prishtina, Kosova. ${ }^{3}$ Department of Pharmacology, Faculty of Medicine, University of Prishtina, \\ Clinical Centre, Prishtina, Kosova. Email: adnan.bozalija@uni-pr.edu
}

Received: 22 July 2020, Revised and Accepted: 25 August 2020

ABSTRACT

Objective: This study aimed to determine the effects of indoor air pollution on workers and the effects of discharged gases, such as $\mathrm{CO} \mathrm{CO}_{2}$, $\mathrm{NO}_{2}$, $\mathrm{O}_{3}$, $\mathrm{SO}_{2}, \mathrm{NH}_{3}$, and $\mathrm{PM}$, on the manifestation of bronchial reactivity during the process of gasification at the power plants in Kastriot, Kosovo.

Methods: Parameters of lung function were determined using body plethysmography. Airway resistance (Raw) and intrathoracic gas volume (ITGV) were measured; based on these values, specific airway resistance (SRaw) and specific airway conductance were calculated.

Results: The study was performed in two groups: the control group and the experimental group. The control group consisted of 32 healthy people, whereas the experimental group consisted of 55 workers of the gasification department of the power plants in Kastriot, Kosovo. The results of this study indicated that the mean value of SRaw significantly increased in the experimental group $(\mathrm{p}<0.05)$ compared to the control group ( $p>0.1)$. This study also showed that smoking is in favor of the negative effects of air pollution at the premises of the gasification department ( $\mathrm{p}<0.01)$. Measurements of the respiratory systems were made before and following provocation with histamine-aerosol $(1 \mathrm{mg} / \mathrm{ml})$ in the control and experimental groups. Changes between these two groups following this provocation with histamine-aerosol were found to be statistically significant ( $\mathrm{p}<0.01)$.

Conclusion: Although air pollution requires time to cause a respiratory pathology, it permanently affects the manifestation of bronchial reactivity. This finding suggests that the real situation of these workers exposed to air pollution during the process of gasification poses a serious risk to their health and particularly to normal respiratory function.

Keywords: Power plants of Kosovo, Workers during the process of gasification, Respiratory health.

(c) 2020 The Authors. Published by Innovare Academic Sciences Pvt Ltd. This is an open access article under the CC BY license (http://creativecommons. org/licenses/by/4. 0/) DOI: http://dx.doi.org/10.22159/ajpcr.2020.v13i10.39178

\section{INTRODUCTION}

Air pollution has been a long time problem, but only in recent decades, it has been given relevant importance. Although numerous studies in this field have been reported, questions regarding the relationship between pathological changes and the deleterious effect of nitrogen oxide (NOx) in the workplace remain [1].

The effect of NOx causes hyperemia, edema, and hypertrophy of the bronchial mucosa, increased secretion of the glandular apparatus, and bronchial musculature tonus, which certainly causes damage to the ventilatory function of the lungs [2]. Chronic obstructive pulmonary disease (COPD) is one of the leading causes of death and disability worldwide. According to the WHO forecasts, COPD will become the fourth leading cause of mortality in the world by 2030 [3].

The main gaseous pollutants released during the gasification process by power plants are carbon monoxide and dioxide $\left(\mathrm{CO}\right.$ and $\left.\mathrm{CO}_{2}\right)$, nitrogen dioxide $\left(\mathrm{NO}_{2}\right)$, ozone $\left(\mathrm{O}_{3}\right)$, and sulfur dioxide $\left(\mathrm{SO}_{2}\right)$. Other important gaseous pollutants are ammonia and volatile organic compounds (e.g., methane, benzene, and chlorofluorocarbon) [4].

Air pollution has become the leading environmental cause of premature deaths [5]. Global estimates show that external pollution and indoor environments cause 1.15 million deaths worldwide (corresponding to nearly $2 \%$ of the total death toll) [6].

The harmful effects of $\mathrm{O}_{3}, \mathrm{NO}_{2}$, and particulate matter (PM), as well as the pollution of the traffic, in general, on respiratory symptoms and functions, are well documented. In addition to strong epidemiological evidence of a link between air pollution and asthma, recent studies, especially in urban areas, have shown the role of pollutants in the development of asthma and COPD $[7,8]$.

Air pollution can also increase the risk of pneumonia by impairing the function of alveolar pulmonary macrophages and epithelial cells [9].

The interaction of air pollutants and their effect on bronchial hyperreactivity indicate that $\mathrm{SO}_{2}$ and $\mathrm{O}_{3}$ increase bronchial hyperreactivity. $\mathrm{SO}_{2}$ concentrations up to $0.5 \mathrm{ppm}$ and $\mathrm{O}_{3}$ concentrations up to 0.2 ppm have shown this effect [10].

Studies have shown that respiratory obstruction and increased bronchial reactivity are present in the early lives of children who develop asthma [11].

Exposure to air pollution has been associated with increased cardiovascular disease (CVD), and the biological mechanism of oxidative stress and systemic inflammation plays an important role. Heart rate, systolic blood pressure, diastolic blood pressure, white blood cells, red blood cells, hematocrit, and hemoglobin are several biomarkers of CVDrelated oxidative stress and systemic inflammation [12].

Air pollution poses a potential risk for increased lung cancer risk. The link between exposure to air pollution at work and lung cancer risk indicates that long-term exposure to workplace environmental pollution can cause lung cancer [13].

Oral, pharyngeal, and laryngeal cancers are linked to smoking and may also be linked to other sources of air pollution [14]. 
In Kosovo, the air quality has severely deteriorated in developed urban areas, especially in industrial power plants. The greatest impact on the environment is caused by Kosovo Energy Corporation power plants (TC-A and TC-B), industries (releasing gases at workplaces, surface mines, cement plants, etc.), and small ones. Pollution, however, is also caused by individual heating facilities [15].

On this basis, the essential purpose of our study is to compare the bronchial reactivity between healthy individuals and those exposed to high levels of gas-polluted air pollution in the workplace during the gasification process in Kosovo's power plants. The most direct air pollution damage is, undoubtedly, reflected in the respiratory system; thus, all our study is focused on this system.

\section{METHODS}

Our study focused on detailed research to validate all cases verified with increased bronchial reactivity and COPD by examining the respiratory system as per the Medical Research Council (MRC) [16] questionnaire for COPD by recording the degree of pulmonary function impairment. Hence, we have ascertained the phenomenon of increased bronchial reactivity and COPD by measuring the objective parameters of the workers of the gasification department in the Kosovo power plants.

Research at workplaces with exposure to different gases shows large differences in the prevalence of increased bronchial reactivity and obstructive pulmonary disease such as different habits, smoking, working conditions, and workplaces.

Smoker and nonsmoker plethysmography values of the examined workers indicate an increasing tendency with increasing age and duration of exposure to harmful NOx in the workplace. It is important to note that there are statistically significant differences between smokers and nonsmokers. There are also statistically significant differences in these values compared to those of individuals suffering from chronic obstructive bronchitis and those without chronic obstructive bronchitis, which reduces the relevance of the MRC questionnaire [17].

The individual selection was randomized, and all research participants were informed about the procedures and purpose of the research.

All individuals who were part of the research were informed in advance to not administer any drugs at least $48 \mathrm{~h}$ before the examination to avoid interference with our test results. Thus, pulmonary functions are determined in tranquility. Specific airway resistance (SRaw) and intrathoracic gas volume (ITGV) measurements were then measured using body plethysmography. Based on the SRaw and ITGV values obtained, airway resistance (Raw) and specific airway conductance (SGaw) were calculated.

In the control group, we also applied an additional procedure to verify that the selected individuals were indeed healthy and did not possess bronchial reactivity in the respiratory tract airways. We demonstrated this by performing a bronchoconstriction provocation test with bronchoconstriction agents such as histamine. In our case, we have used histamine for airway constriction.

Relatively large numbers of patients are due to the interaction of many factors such as poor climatic conditions in the workplace, smoking, poor socioeconomic conditions, and inadequate medical care.

The research was carried out in two working groups: The control group and the experimental group. The control group included 32 healthy people, whereas the experimental group included 57 workers, with permanent work in the gasification process department at power plants in Kastriot, Kosovo.

Plethysmography is sophisticated equipment that measures the volume of air in the sternum. This equipment consists of a plastic booth dedicated to the individual entering to perform the measurements. Subject blows into a turbine, which, like spirometry, records the volumes and airflows that this subject performs. Using plethysmography, we can record the pressure-pressure curves as well as the pressure-flow curves. Calculate the ratios between cabin air pressures and airway pressures, and the pressure-flow curve is calculated as the ratio between the pressure in the booth and airflow in the airways. The main parameters we measure using a plethysmograph are the volumes of gases in the sternum, namely, ITGV. Hence, the volumes of air in the respiratory system can be calculated as well as the amount of air remaining in the alveolar cysts. Other very important parameters that are measured using a plethysmograph are the airway resistance (Raw). These are calculated by the pressure difference at the beginning and end of the airway when the flow passing through them is $1 \mathrm{l} / \mathrm{s}$. These parameters indicate the level of obstacle faced by the air when breathing (inspirium-expirium). SRaw is calculated as the ratio between Raw and ITGV. Another parameter is SGaw, which represents the ratio of $1 /$ SRaw.

If changes in the respiratory system are found, an appropriate treatment with drugs is initiated immediately. Drugs used to treat bronchial asthma and COPD was:

a. Bronchodilator and

b. Anti-inflammatory drugs

Bronchodilator drugs: Beta-2 adrenergic agonists, methylxanthines, and anticholinergic drugs [18-20].

Anti-inflammatory drugs: Corticosteroids, antihistamines, and antileukotrienes [21-23].

As medical treatment of these diseases is limited, the only option is to take preventive measures [24-26].

This scientific study is about the difference between the two research groups. On this basis, we used the t-test as a differentiation mechanism regarding the level of significance between the two groups: The control group and the experimental group (gasification department workers). In the control group, we have two sets of plethysmography values, which were obtained as a result of pre- and post-provocation histamine measurements of individuals in the same group.

Statistical processing involves the determination of mean (X), standard deviation (SD), and standard error of the mean, as well as testing of statistical differences between workers and control group. Statistical method ANOVA was used for analysis. The ANOVA test was used to analyze the differences between the results obtained within the group.

The parameters are summarized in MS-EXCEL. The results obtained were tested using Student's t-test to ascertain significant differences between the experimental and control groups. Statistical software INSTAT-3 and STATISTICA for Windows have been used.

\section{RESULTS}

We believe that the tracheobronchial system showed no sensitivity in healthy individuals; therefore, they can be used as a special control group to evaluate the condition of the experimental group. General data of the individuals of both groups are given in Tables 1 and 2 and Diagram 1.

Initially, we present the plethysmography results of the control group to avoid suspicions about the presence of bronchial reactivity in this group. These results are expressed in two series, before and after provocation with histamine bronchoconstriction test (Fig. 1).

Statistical calculation with a t-test shows no significant difference $(p>0.1)$ in healthy individuals before and after provocation with histamine. The SRaw and SGaw between the control and experimental groups were significantly different $(\mathrm{p}<0.05)$. The results show a pronounced presence of bronchial reactivity of workers who worked on 
Table 1: General characteristics of the subjects

\begin{tabular}{|c|c|c|c|c|c|c|}
\hline Group & $\mathbf{n}$ & Age (years) & Height $(\mathrm{cm})$ & Weight (kg) & VC (L) & $\mathrm{FEV}_{1}(\mathrm{~L})$ \\
\hline Control & 32 & $22.8 \pm 0.45$ & $175 \pm 0.37$ & $68.5 \pm 1.8$ & $3.80 \pm 0.12$ & $3.82 \pm 0.12$ \\
\hline Experimental & 55 & $38.54 \pm 1.33$ & $175.67 \pm 0.54$ & $70.80 \pm 1.22$ & $3.90 \pm 0.11$ & $3.68 \pm 0.12$ \\
\hline
\end{tabular}

Generalized mean values for: Control group $n=32, \mathrm{X} \pm$ standard error of the mean; Experimental group $n=55, \mathrm{X} \pm$ standard error of the mean. The general starting values

for VC (L) and FEV1 (L) are also given. VC: Vital capacity expressed in liters, $\mathrm{FEV}_{1}$ : Enhanced expiratory volume in the $1^{\text {st }} \mathrm{s}$, expressed in liters

Table 2: Body-plethysmography features of individuals involved in the study

\begin{tabular}{llllll}
\hline Group & $\mathbf{n}$ & $\begin{array}{l}\text { Raw } \\
(\mathbf{k P a} \times \mathbf{s} / \mathrm{L})\end{array}$ & ITGV (L) & $\begin{array}{l}\text { SRaw } \\
(\mathbf{k P a} \times \mathbf{s})\end{array}$ & $\begin{array}{l}\text { SGaw } \\
(\mathbf{k P a} \times \mathbf{s})\end{array}$ \\
\hline Control & 32 & $0.17 \pm 0.5$ & $3.05 \pm 0.3$ & $0.51 \pm 0.3$ & $1.96 \pm 0.13$ \\
Experimental & 55 & $1.15 \pm 0.7$ & $3.55 \pm 0.6$ & $4.08 \pm 0.8$ & $2.24 \pm 0.18$ \\
\hline
\end{tabular}

Raw (kPa×S/L); ITGV (L); SRaw: Raw×ITGV; SGaw: 1/SRaw, Raw: Airway resistance expressed in kilopascal/s/liter, ITGV: Volume of intrathoracic gas expressed in liters, SRaw: Specific airway resistance, which is the relationship between resistance and the volume of intrathoracic gas, SGaw: Expresses the relationship between 1 /specific resistances. SGaw can also be referred to as specific airway passage or conductivity

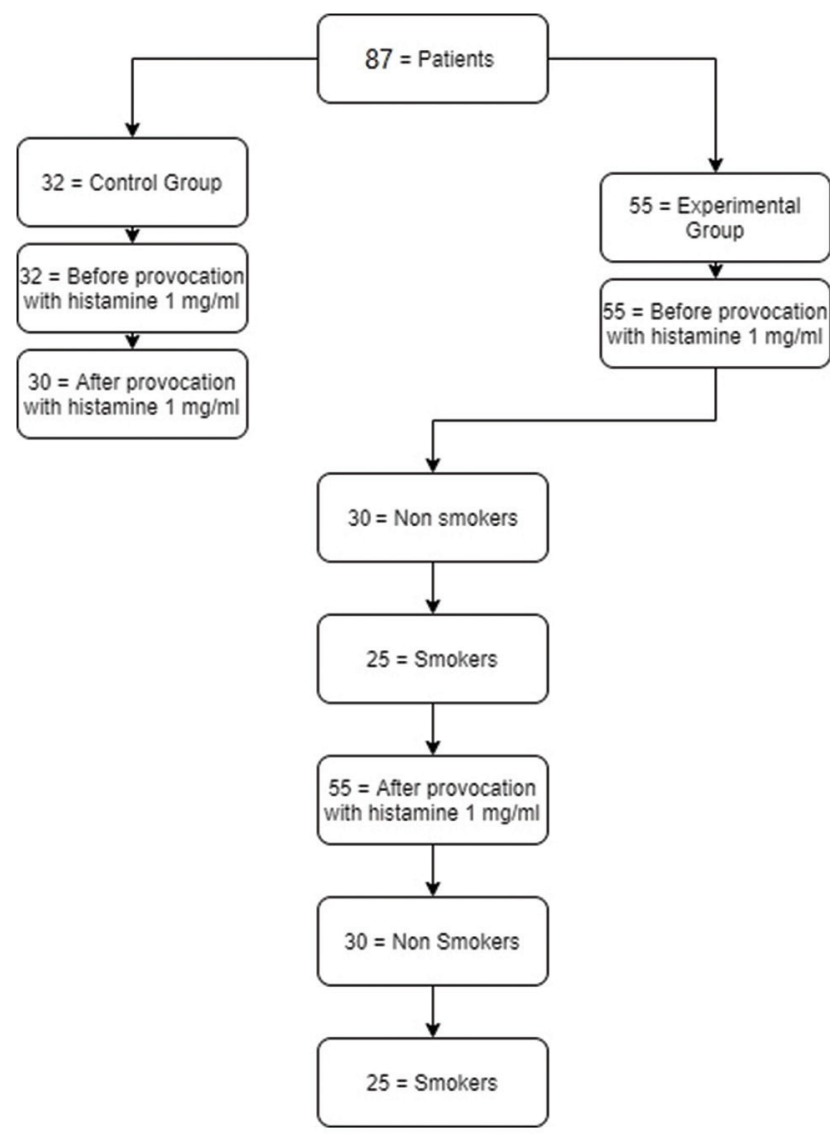

Diagram 1: People's participation frequency of the control and experimental group in the experiment

the gasification process in Kosovo's power plants. The values of SRaw and SGaw for the research groups are shown in Figs. 2 and 3.

\section{DISCUSSION}

There is comprehensive literature on the health effects of gas pollutants in the workplace, including numerous epidemiological and toxicological studies. In each special study, there is a relationship between gaseous air pollution in the workplace and one or more other factors, depending on the level of exposure, the health status of the workers exposed, and their age.

Scientific evidence on the health effects of gaseous air pollution at workplaces has been increasing in recent years. Some questions remain open, but many epidemiological studies have shown the importance of air pollution in workplaces as a risk factor for their mortality and morbidity [27]. The impact of air pollutants on the respiratory tract has been widely and consistently reported in recent years [28].

Air pollution has broad systemic effects on the human body, affecting both the respiratory and cardiovascular systems through multiple mechanisms, including oxidative stress, inflammation, and endothelial dysfunction [29]. The correlation between air pollution and cardiorespiratory diseases is a global concern [30].

Statistical calculation of SRaw and SGaw was performed for the control and experimental group, indicating a significant difference between these groups $(p<0.05)$. The presence of emphasized bronchial reactivity in the workers working in the gasification department at the Kosovo power plants has been registered.

The difference between the experimental subgroups confirmed the favorable impact of smoking on exacerbating the negative respiratory effects of air pollution at the gasification department of the power plant $(\mathrm{p}<0.01)$.

Due to indoor ventilation, employees who work indoors are subjected to the elimination of gases released by the ventilation system during the gasification process. The workers were less affected from bronchial reactivity than the residents who live near power plants as these workers leave the environment where they work after $8 \mathrm{~h}$ of work and travel farther away from the power plants where they live (up to $50 \mathrm{~km}$ away), with less air pollution or no pollution at all. This may also be the cause for lower susceptibility of bronchial reactivity in these workers $(p<0.05)$ compared to residents who live near the power plants and are, therefore, constantly exposed to irritants for $24 \mathrm{~h}$, which is manifested with emphasized bronchial reactivity $(\mathrm{p}<0.01)$, greatly endangering health [31]

In addition to cardiopulmonary morbidity and mortality, recent studies have found that air pollution is also associated with health effects, such as dementia, structural brain changes in children, cognitive impairments, and diabetes [32]

There is strong evidence that air pollution with different gases in the workplace exacerbates asthma morbidity and mortality in individuals with the disease and there is some evidence that air pollution with gases may affect asthma prevalence [33]. Children are at greater risk of developing asthma when exposed to higher concentrations of air pollutants [34].

A study carried out in continental France found that $9 \%$ of total mortality in France is due to anthropogenic $\mathrm{PM}_{25}$ [35]. The calculated total mortality for $\mathrm{PM}_{2.5}$ is higher than that due to $\mathrm{PM}_{10}[36]$.

The American Heart Association published a "Scientific Statement" stating that "there is a correlation between $\mathrm{PM}_{25}$ exposure and mortality - cardiovascular morbidity" [37].

In addition, a new health outcome in the United States showed that the incidence of lung cancer is related to exposure to $\mathrm{PM}_{2.5}$ particles [38]. 


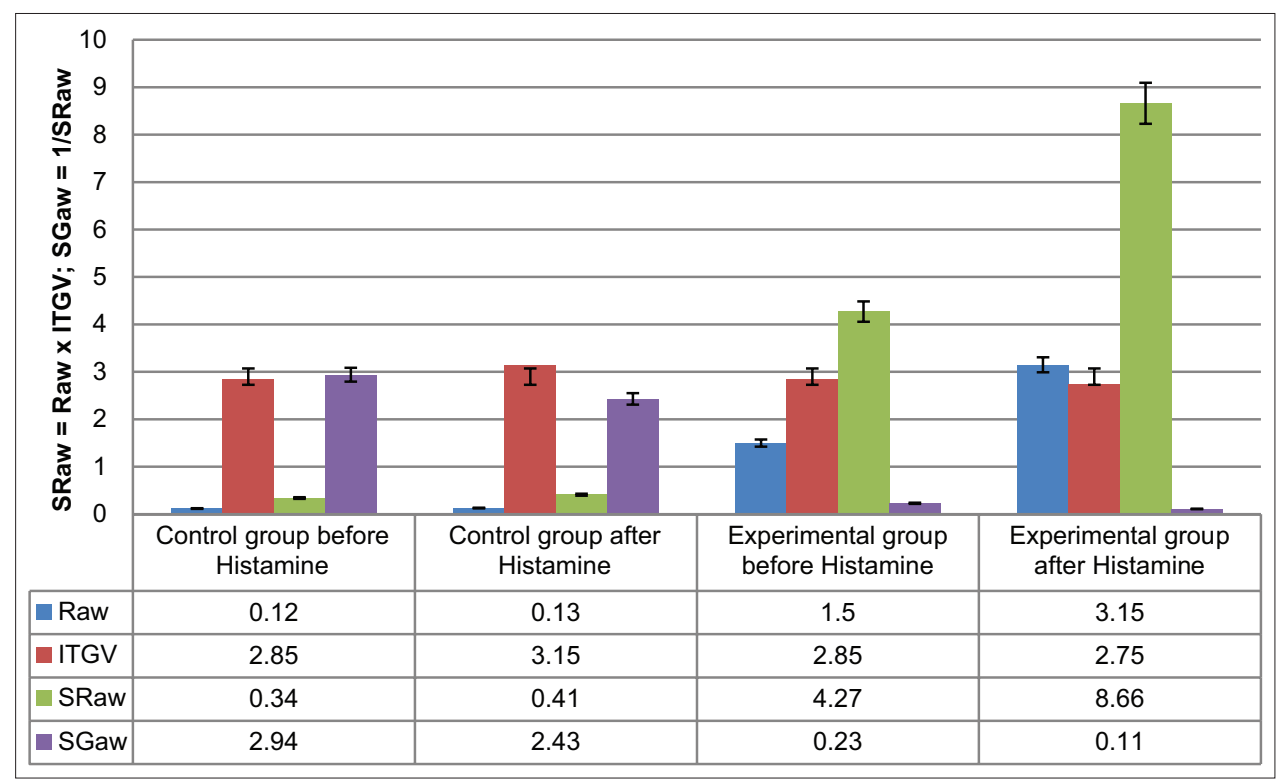

Fig. 1: Control and experimental group before and after provocation. Comparison of values of specific airway resistance and specific airway conductance in between the control group ( $p>0.1 ; n=32 ; X \pm$ standard error of the mean) and experimental group $(n=55 ; X \pm s t a n d a r d$ error of the mean). $(p<0.05)$

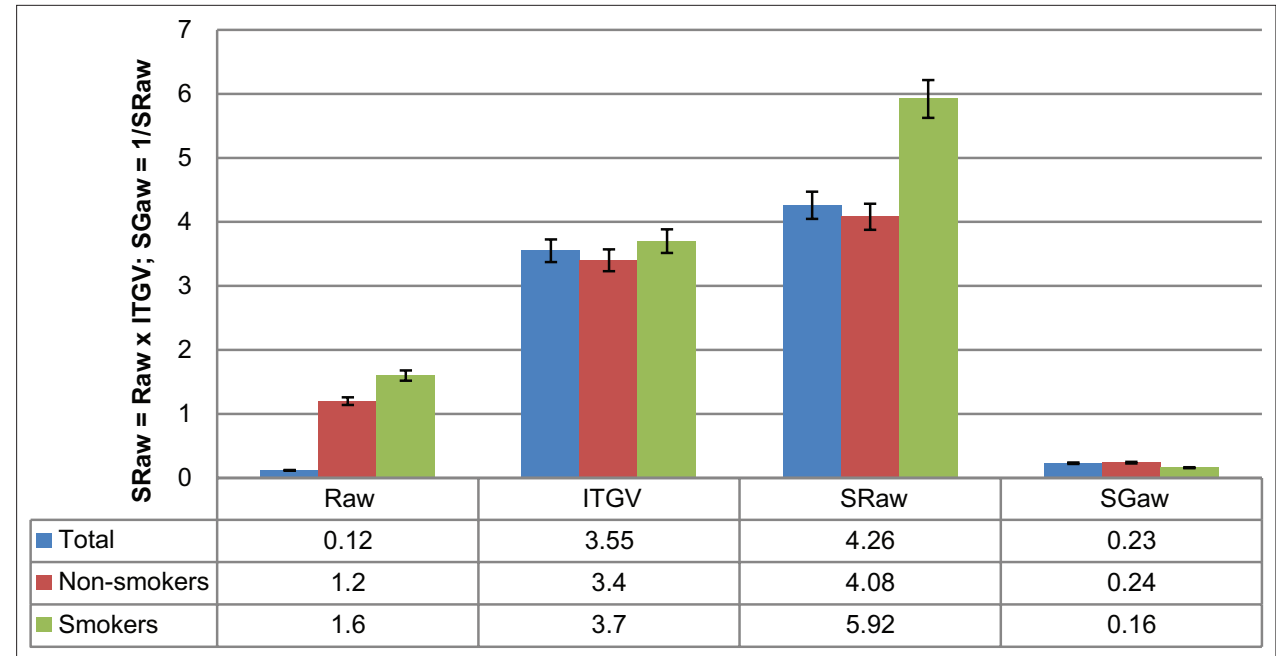

Fig. 2: Researched by non-smoker and smoker categories (before provocation with histamine). Comparison of specific airway resistance and specific airway conductance values between smokers and non-smokers before provocation with histamine ( $n=55$; $X \pm s t a n d a r d$ error of the mean; $(\mathbf{p}<0.05)$

In the American Cancer Society study, the incidence of lung cancer

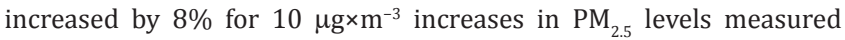
between cities [39]. $\mathrm{PM}_{2.5}$ was also associated with decreased parathyroid hormone in exposed individuals [40].

In addition to $\mathrm{CO}$ and $\mathrm{CO}_{2}$, other pollutants, including $\mathrm{NO}_{2}$ and $\mathrm{O}_{3}$, were also associated with workplace mortality [41]. $\mathrm{SO}_{2}$ has also been associated with increased mortality and morbidity. Significant effects of $\mathrm{SO}_{2}$ and cardiopulmonary mortality have been observed [42].

$\mathrm{NO}_{2}$ concentrations are related to mortality rate and mortality is caused by cardiovascular and respiratory morbidity and lung cancer [43].

According to a study conducted in Copenhagen, Denmark, reducing $\mathrm{NO}_{2}$ exposure by reducing traffic-related air pollution will reduce the incidence and prevalence of chronic CVD, respiratory, and lung cancers, thereby increasing life expectancy [44].
A study was conducted to ascertain the link between $\mathrm{O}_{3}$ and mortality in 21 European cities and found that the $10 \mathrm{ppb}$ increase in the 2-day 8-h $\mathrm{O}_{3}$ average was $0.31 \%$ ( $95 \%$ confidence interval [CI]: $0.17 \%, 0.52 \%$ ), $1.13 \%$ ( $95 \%$ CI: $0.74 \%, 1.51 \%$ ), and $0.46 \%$ (95\% CI: $0.22 \%, 0.73 \%$ ) increase in total respiratory and cardiovascular mortality in summer [45].

Acute and inflammatory changes caused by sudden exposure to high concentrations of irritating gas or steam are associated with bronchoconstriction, manifested by dyspnea, and chest pain. Chronic inflammatory changes caused by constant or intermittent effects of moderately increased concentrations of soluble $\left(\mathrm{HCl}, \mathrm{SO}_{2}, \mathrm{NH}_{3}\right.$, and the like) or less soluble irritants $\left(\mathrm{O}_{3}\right.$, NOx, etc.) have been associated with variable airway reactivity. Different gases through their chlorides and carbon-containing compounds cause changes throughout the bronchial trunk and reversible bronchoconstriction that can be measured. The markedly increased trunk reactivity of the airways causes exposure to proteolytic enzymes. The inflammatory process associated with COPD is characterized by an increased number 


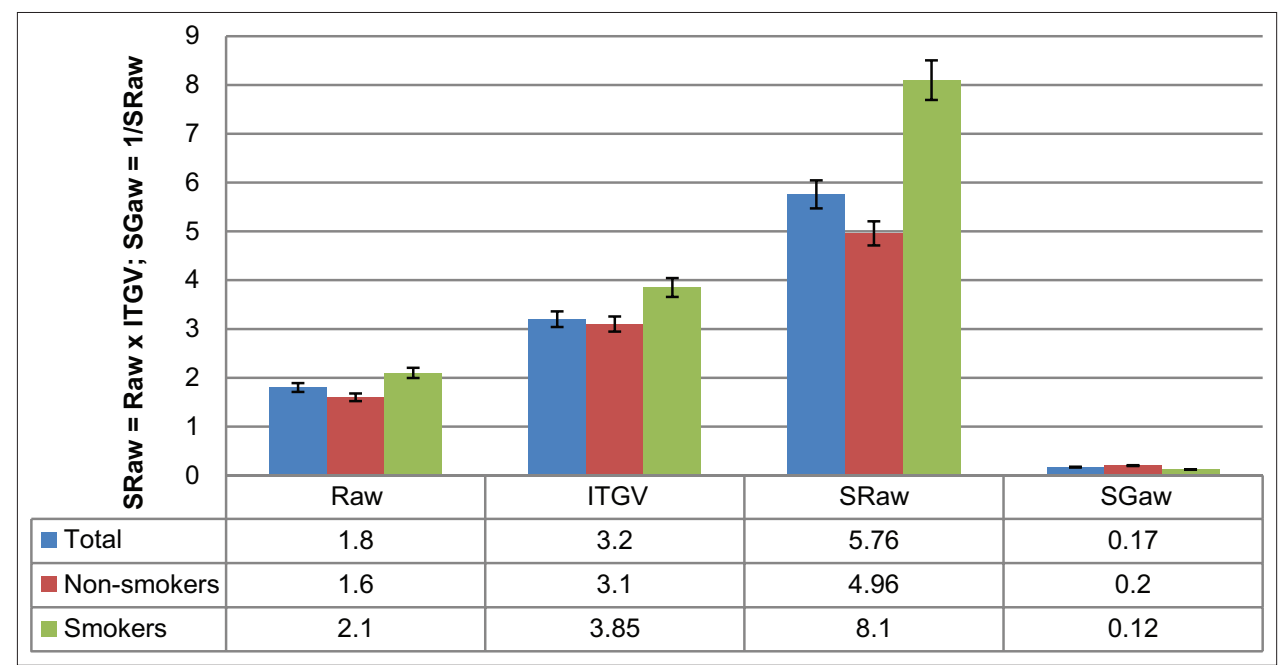

Fig. 3: Researched by non-smoker and smoker categories (after provocation with histamine). Comparison of specific airway resistance and specific airway conductance values between smokers and non-smokers after provocation with histamine $(n=55 ; X \pm s t a n d a r d$ error of the mean; $(p<0.01)$

of activated alveolar macrophages, neutrophils, cytotoxic CD8+T lymphocytes, B lymphocytes, CD4+T lymphocytes, and the release of numerous inflammatory mediators (leukotrienes, cytokines, growth factors, chemokines, and oxidants). Chronic inflammation leads to a reconfiguration of small airways with lumen blockage due to increased mucus production and thickening of the airway walls due to edema and collagen formation, causing fibrosis and constriction [46].

Based on the research and results obtained, it can be concluded that continuous monitoring of the respiratory tract is necessary, especially because of the presence of an inflammatory reaction that occurs after prolonged exposure to the pollutant. These workers must undergo systemic visits and tracheobronchial provocation tests with histamine or methacholine, which is valuable for timely therapeutic intervention. Subjects with bronchial hyperreactivity show a special preference for the rapid onset of permanent changes in the respiratory tract, which is why they should be distinguished as subjects at higher risk.

\section{CONCLUSION}

These studies indicate undoubtedly that long-term exposure of workers at the gasification department of power plants in Kosovo to harmful gases such as carbon monoxide, carbon dioxide, sulfur dioxide, sulfur trioxide, NOx, soot, and other pollutants in the workplace cause the occurrence of respiratory tract inflammation with the release of chemical mediators manifested by bronchial hyper-reactivity.

Determining the value of the reaction against the inhalation of histamine hydrochloride resulted at a higher percentage of increase of bronchial reactivity, which is expressed with the increase in specific resistance (SRaw) and SGaw in groups exposed to toxic gases $(\mathrm{p}<0.05)$ in comparison to control group ( $\mathrm{p}>0.1)$.

Experimental group, as an entirety, and subgroup of smokers indicate about significant changes in the SRaw and SGaw $(\mathrm{p}<0.05)$ in the airways compared to the control group ( $p>0.1)$. The difference between the experimental subgroups confirmed the favorable impact of smoking in exacerbating the negative respiratory effects of air pollution $(p<0.01)$.

Based on the research and the results obtained, it can be concluded that permanent monitoring of the respiratory tract is required, especially from the point of view of the presence of inflammatory reaction following prolonged exposure to environmental pollutants. People with increased bronchial hyperreactivity indicate a special predisposition for a quick manifestation of permanent changes in the respiratory tract, and this is just the reason of why they can be singled out as subjects with the highest riskiness.

\section{AUTHORS' CONTRIBUTIONS}

PI conducted the literature search and determined studies for exclusion and inclusion. $A B$ extracted data from the included studies, performed the meta-analysis, and drafted the manuscript. HI conceived the idea for the study, designed the study, and critically revised the manuscript for important intellectual content. All authors contributed to data analysis, drafting and revising the article, gave final approval of the version to be published, and agree to be accountable for all aspects of the work.

\section{CONFLICTS OF INTEREST}

No conflicts of interest were declared by the authors.

\section{AUTHORS' FUNDING}

This manuscript is funded by the authors.

\section{REFERENCES}

1. Brauer M, Avila-Casado C, Fortoul TI, Vedal S, Stevens B, Churg A. Air pollution and retained particles in the lung. Environ Health Perspect 2001;109:1039-43.

2. Goldberg MS, Burnett RT, Valois MF, Flegel K, Bailar JC $3^{\text {rd }}$, Brook J, et al. Associations between ambient air pollution and daily mortality among persons with congestive heart failure. Environ Res 2003;91:8-20.

3. Pauwels RA, Buist AS, Calverley PM, Jenkins CR, Hurd SS, GOLD Scientific Committee. Global strategy for the diagnosis, management, and prevention of chronic obstructive pulmonary disease. NHLBI/ WHO global initiative for chronic obstructive lung disease (GOLD) workshop summary. Am J Respir Crit Care Med 2001;163:1256-76.

4. Traboulsi H, Guerrina N, Iu M, Maysinger D, Ariya P, Baglole CJ. Inhaled pollutants: The molecular scene behind respiratory and systemic diseases associated with ultrafine particulate matter. Int J Mol Sci 2017;18:243

5. Robert J. Laumbach, Kipen HM. Respiratory health effects of air pollution: Update on biomass smoke and traffic pollution. J Allergy Clin Immunol 2012;129:3-11.

6. Kelly FJ, Fussell JC. Air pollution and public health: Emerging hazards and improved understanding of risk. Environ Geochem Health 2015;37:631-49.

7. Provisional Institutions of Self-Government. Ministry of Environment and Spatial Planning. Vol. 14. Kosovo: Kosovo State of the Environment Report; 2003. p. 81-4.

8. Kelly FJ, Fussell JC. Air pollution and airway disease. Clin Exp Allergy 2011;41:1059-71.

9. Neupane B, Jerrett M, Burnett RT, Marrie T, Arain A, Loeb M. Long- 
term exposure to ambient air pollution and risk of hospitalization with community-acquired pneumonia in older adults. Am J Respir Crit Care Med 2010;181:47-53.

10. Pierson WE, Covert DS, Koenig JQ. Air pollutants, bronchial hyperreactivity, and exercise. J Allergy Clin Immunol 1984;73:717-21.

11. Hallas HW, Chawes BL, Rasmussen MA, Arianto L, Stokholm J, Bønnelykke K, et al. Airway obstruction and bronchial reactivity from age 1 month until 13 years in children with asthma: A prospective birth cohort study. PLoS Med 2019;16:e1002722.

12. Martoni AA. Air pollution and cancer. In: Capello F, Gaddi A, editors. Clinical Handbook of Air Pollution-Related Diseases. Cham: Springer; 2018.

13. Fuentes-Leonarte V, Ballester F, Tenías JM. Sources of indoor air pollution and respiratory health in preschool children. J Environ Public Health 2009;2009:727516.

14. Liang B, Yu X, Mi H, Liu D, Huang Q, Tian M. Health risk assessment and source apportionment of VOCs inside new vehicle cabins: A case study from Chongqing, China. Atmos Pollut Res 2019;10:1677-84.

15. United Nations Environment Programme. Office for the Coordination of the Humanitarian Affairs, OCHA, Assessment Mission KosovoSerbia, Report Industrial Complex in Obilić-Power Plant. Vol. 3. Geneva: United Nations Environment Programme; 2003. p. 9-10.

16. MRC Asthma UK. Centre in Allergic Mechanisms of Asthma. United Kingdom: Medical Research Council; 2018.

17. Austoker J, Bryder L, editors. Historical Perspectives on the Role of the MRC: Essays in the History of the Medical Research Council of the United Kingdom and its Predecessor, the Medical Research Committee. Oxford: Oxford University Press; 1989.

18. Islami H, Ilazi A, Gashi N, Mustafa L, Maloku H, Jashanica A. Response of the adrenergic system after provoked bronchoconstriction in patients with bronchial asthma. Acta Inform Med 2014;22:107-10.

19. Hyseini K, Iljazi A, Morina N, Iljazi F, Islami H. Comparison of methylxanthines (doxofylline and diprophylline) effect in patients with bronchial hyperreactivity and bronchial asthma. Res J Pharm Biol Chem Sci 2017;5:500-9

20. Islami H, Veseli H, Behluli E, Morina N. Importance of the adrenergic nerve system in the response of gases in the arterial blood following the provoked bronchospasm. Med Arch 2012;66:292-5.

21. Lajqi N, Ilazi A, Kastrati B, Islami H. Comparison of glucocorticoid (budesonide) and antileukotriene (montelukast) effect in patients with bronchial asthma determined with body plethysmography. Acta Inform Med 2015;23:347.

22. Morina N, Iljazi A, Iljazi F, Hyseini K, Bozalia A, Islami H. Effect of antileukotriene (zileuton) in patients with bronchial asthma (emphasized reactors, moderate reactors, and non-reactors). Res J Pharm Biol Chem Sci 2017;8:334-42.

23. Morina N, Iljazi A, Iljazi F, Gashi L, Bozalija A, Rustemi F, et al. Effect antileukotriene substances (montelukast) in patients with changed bronchial reactivity (non-reactors, moderate reactors and emphasized reactors). Res J Pharm Biol Chem Sci 2018;8:1092-9.

24. Morina N, Haliti A, Iljazi A, Islami D, Bexheti S, Bozalija A, et al. Comparison of effect of leukotriene biosynthesis blockers and inhibitors of phosphodiesterase enzyme in patients with bronchial hyperreactivity. Open Access Maced J Med Sci 2018;6:777-81.

25. Haxhiu MA, Islami H, Mandura I, Krasniqi A. The protective effect of oxatomide (R 35 443) on exercise-induced asthma. Plucne Bolesti Tuberk 1980;32:122-7.

26. Islami P, Ilazi A, Jakupi A, Bexheti S, Islami H. Importance of alphaadrenergic receptor subtypes in regulating of airways tonus at patients with bronchial asthma. Acta Inform Med 2014;22:174-8.
27. Mayoralas-Alises S, Diaz-Lobato S. Air pollution and lung cancer. In: Current Respiratory Medicine Reviews. Vol. 8. Sharjah: Bentham Science Publishers; 2012. p. 418-29.

28. Raaschou-Nielsen O, Andersen ZJ, Hvidberg M, Jensen SS, Ketzel M, Sørensen M, et al. Air pollution from traffic and cancer incidence: A Danish cohort study. Environ Health 2011;10:67.

29. Kjellstrom TE, Neller A, Simpson RW. Air pollution and its health impacts: The changing panorama. Med J Aust 2002;177:604-8.

30. Martuzzi M, Krzyzanowski M, Bertollini R. Health impact assessment of air pollution: Providing further evidence for public health action. Eur Respir J Suppl 2003;40:86s-91s.

31. Haliti A, Islami P, Mustafa L, Dauti A, Bozalija A, Islami H. Effect of air pollutants on the manifestation of bronchial reactivity in a population living in proximity to a power plant. Toxicol Int 2018;25:1-9.

32. Faustini A, Stafoggia M, Colais P, Berti G, Bisanti L, Cadum E, et al. Air pollution and multiple acute respiratory outcomes. Eur Respir J 2013;42:304-13

33. Yap J, Ng Y, Yeo KK, Sahlén A, Lam CS, Lee V, et al. Particulate air pollution on cardiovascular mortality in the tropics: Impact on the elderly. Environ Health 2019;18:34.

34. Requia WJ, Adams MD, Arain A, Papatheodorou S, Koutrakis P, Mahmoud M. Global association of air pollution and cardiorespiratory diseases: A systematic review, meta-analysis, and investigation of modifier variables. Am J Public Health 2018;108:S123-30.

35. Greven FE, Vonk JM, Fischer P, Duijm F, Vink NM, Brunekreef B. Air pollution during new year's fireworks and daily mortality in the Netherlands. Sci Rep 2019;9:5735.

36. Williams AM, Phaneuf DJ, Barrett MA, Su JG. Short-term impact of $\mathrm{PM}_{2.5}$ on contemporaneous asthma medication use: Behavior and the value of pollution reductions. Proc Natl Acad Sci USA 2019;116:5246-53.

37. Prunicki M, Stell L, Dinakarpandian D, de Planell-Saguer M, Lucas RW, Hammond $\mathrm{SK}$, et al. Exposure to $\mathrm{NO}_{2}, \mathrm{CO}$, and $\mathrm{PM}_{25}$ is linked to regional DNA methylation differences in asthma. Clin Epigenetics 2018;10:2.

38. Sanyal S, Rochereau T, Maesano CN, Com-Ruelle L, Annesi-Maesano I. Long-term effect of outdoor air pollution on mortality and morbidity: A 12-year follow-up study for metropolitan France. Int J Environ Res Public Health 2018;15:2487.

39. Samek L. Overall human mortality and morbidity due to exposure to air pollution. Int J Occup Med Environ Health 2016;29:417-26.

40. Lipfert FW. Long-term associations of morbidity with air pollution: A catalog and synthesis. J Air Waste Manag Assoc 2018;68:12-28.

41. Cromar KR, Gladson LA, Ewart G. Trends in excess morbidity and mortality associated with air pollution above American thoracic societyrecommended standards, 2008-2017. Ann Am Thorac Soc 2019;16:836-45.

42. Pereza L, Rappa R, Künzlia N. The year of the lung: Outdoor air pollution and lung health. Swiss Med Wkly 2010;140:w13129.

43. Peden DB. The unexpected health effects of air pollution. N C Med J 2018;79:309-11.

44. Lavigne E, Burnett RT, Weichenthal S. Association of short-term exposure to fine particulate air pollution and mortality: Effect modification by oxidant gases. Sci Rep 2018;8:16097.

45. Kan H, Wong CM, Vichit-Vadakan N, Qian Z. Short-term association between sulfur dioxide and daily mortality: The public health and air pollution in Asia (PAPA) study. Environ Res 2010;110:258-64.

46. Saetta M, Di SA, Turato G, Facchini FM, Corbino L, Mapp CE, et al. CD8+ T-lymphocytes in peripheral airways of smokers with chronic obstructive pulmonary disease. Am J Respir Crit Care Med 1998;157:822-6. 